\title{
Traumatic wound dehiscence following penetrating keratoplasty
}

\author{
TREXLER M. TOPPING, ${ }^{1}$ WALTER J. STARK,${ }^{2}$ EDWARD MAUMENEE ${ }^{2}$ AND \\ KENNETH R. KENYON ${ }^{3}$
}

From the ${ }^{1}$ Retina and Vitreous Service, Department of Ophthalmology, Medical College of Wisconsin, Milwaukee, Wisconsin; the ${ }^{2}$ Wilmer Ophthalmological Institute, Baltimore, Maryland; and the ${ }^{3}$ Department of Ophthalmology, Harvard Medical School, the Cornea Service, Massachusetts Eye and Ear Infirmary, and the Department of Cornea Research and Morphology Unit, Eye Research Institute of the Retina Foundation, Boston, Massachusetts, USA

SUMMARY Four young male patients with keratoconus had traumatic dehiscence of the surgical wound after penetrating keratoplasty. Two were rendered aphakic by the trauma, and in one patient the lens was dislocated posteriorly. In each case the dehiscence was repaired by resuturing the original corneal graft. Despite marked corneal oedema in the immediate postoperative period all four grafts deturgesced and subsequently cleared. The follow-up has been a minimum of 23 months. We recommend therefore primary resuturing of traumatic wound dehiscence after keratoplasty, anterior vitrectomy if the lens is dislodged, and prophylactic antibiotics postoperatively. The clearing of the initially oedematous grafts in each case illustrates the resilience of the corneal endothelium.

Wound separations sometimes occur after penetrating keratoplasty, usually soon after suture removal. ${ }^{12}$ Such wound dehiscences have been particularly associated with grafts for corneal oedema, ${ }^{2}$ use of continuous-suture techniques, ${ }^{2}$ and postoperative elevation of intraocular pressure (IOP). ${ }^{1}$

Friedman $^{3}$ reported keratoplasty wound dehiscence in 2 elderly aphakic ladies after severe, blunt ocular trauma 4 years and 6 years after transplant. In both cases the vision was no light perception, and enucleations were performed, revealing retinal detachment and massive intraocular haemorrhage. Binder et al. ${ }^{1}$ mentioned a traumatic wound separation at 49 weeks after keratoplasty, and Polack and Binder ${ }^{4}$ studied by scanning electron microscopy the transplanted cornea from a male with keratoconus who had a wound dehiscence after ocular trauma one week following suture removal. Raber $e t$ al..$^{5}$ recently reported 12 cases of traumatic wound dehiscence in 10 keratoplasty patients.

At the Wilmer Institute we followed up 4 patients who had undergone traumatic wound dehiscence sustained after penetrating keratoplasty. In each case the transplanted cornea was resutured in position,

Correspondence to Trexler M. Topping, MD, 8700 West Wisconsin Avenue, Milwaukee, Wisconsin 53226, USA. and each subsequently deturgesced completely. This series indicates that primary resuturing of corneal grafts after traumatic dehiscence is the preferred management of such cases.

\section{Case reports}

CASE 1

In 1968 , at age 23 , this male patient with bilateral keratoconus underwent penetrating keratoplasty in the right eye followed in 1969 by a penetrating keratoplasty in the left eye. Both eyes did well postoperatively until 29 November 1975 , when he was struck in the left eye during a bar-room brawl. The corneal graft wound ruptured inferiorly, and the lens was expelled from the eye through the keratoplasty dehiscence. An anterior vitrectomy was performed, and the wound was repaired with interrupted 10-0 monofilament nylon sutures. In October 1977, 23 months after repair, the corrected visual acuity was $6 / 6(20 / 20)$ in the involved eye, and the cornea was clear (Fig. 1).

CASE 2

On 28 July 1972, when he was aged 20 , a $7 \cdot 5 \mathrm{~mm}$ penetrating keratoplasty was performed with $10-0$ 


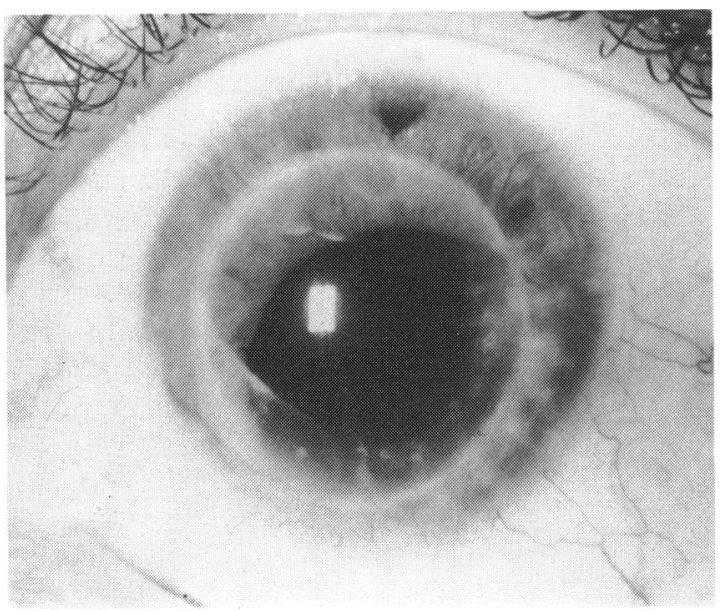

Fig. 1 Four months after repair of sound rupture inferiorly the original graft is clear (case 1).

monofilament nylon interrupted sutures on the patient's right eye for keratoconus. Best visual acuity obtained was 6/9 (20/30). About 10 weeks after keratoplasty he was struck in the operated eye by a Frisbee (a plastic disc thrown in a game). Experiencing immediate pain and decreased vision in the affected eye, he was examined immediately at the Wilmer Institute, where the vision was light perception without projection. The graft was found to be prolapsed and sandwiched between the eyelids but was anchored by 2 or 3 sutures in the inferonasal quadrant. By slit-lamp examination the opaqueappearing cornea was 3 times the normal thickness superiorly and twice the normal thickness inferiorly.

Because suitable donor corneal tissue was not immediately available, the surgeon elected to resuture the existing cornea to serve as a temporary covering graft. This was done with interrupted $10-0$ monofilament nylon sutures. Postoperatively, however, the graft cleared slowly, and 29 months later the patient's visual acuity in the injured eye was $6 / 9(20 / 30)$ with correction. The corneal button was crystal clear, and the corneal thickness was normal at $0.56 \mathrm{~mm}$. The lens was clear, the fundus was normal, and the patient was otherwise asymptomatic and on no medication.

\section{CASE 3}

The patient, a man then aged 24 years, was seen for repeat keratoplasty on his right eye on 26 September 1974. Two years earlier he had undergone thermokeratoplasty, followed by 2 successive penetrating keratoplasties, each of which has succumbed to a homograft reaction. On 26 September 1974 he underwent a $7.5 \mathrm{~mm}$ penetrating keratoplasty with continuous 10-0 monofilament nylon suture, with

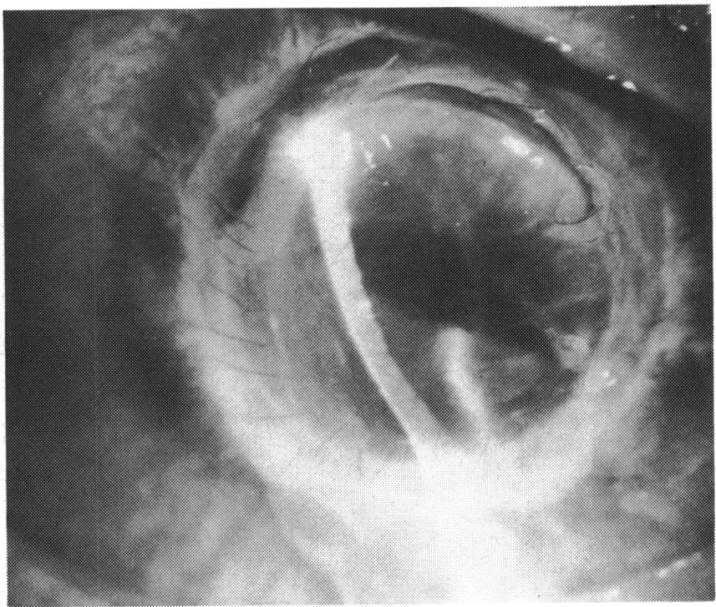

Fig. 2 Iris tissue plugs the keratoplasty-wound dehiscence superiorly 3 days after injury by a champagne cork. Slit-beam shows thickening of the corneal button (case 2).

insertion of a tissue-typed donor cornea preserved in TC-199 medium. The vision at the time of discharge from the hospital was 6/18 (20/60). On 31 December 1974 , about 3 months postoperatively, he was struck in the right eye accidentally with a champagne cork. He was seen by a physician in Florida, who noted that the graft wound had dehisced. On 2 January, 2 days after the injury, he arrived at the Wilmer Institute with a visual acuity of light perception. The anterior chamber was flat superiorly but formed inferiorly. Iris tissue and a considerable amount of fibrin were present in the wound superiorly (Fig. 2) and the graft had dehisced from 8 o'clock to 4 o'clock. There were old keratic precipitates on the posteroinferior surface of the graft. The patient was treated with high-dose systemic antibiotics (penicillin $G$ and nafcillin) intravenously. In the operating room the iris was peeled from the posterior corneal surface. The lens had been subluxed posteriorly and was not retrieved. An anterior vitrectomy was performed. The corneal wound margins were surgically apposed and were sutured with multiple interrupted $10-0$ monofilament nylon sutures. Postoperatively the graft cleared, and in December 1979, 5 years after the injury the visual acuity was 6/6 (20/20) with correction.

\section{CASE 4}

In August 1975, at age 30, this black male was admitted to the Wilmer Institute for penetrating keratoplasty in the left eye. Preoperatively 45 dioptres of left exotropia and high myopia with lattice degeneration of the retina with holes but no detachment in both eyes were noted. He had had thermokeratoplasty in March 1975 for keratoconus. The $7.5 \mathrm{~mm}$ penetrating keratoplasty with a running $10-0$ monofilament nylon 


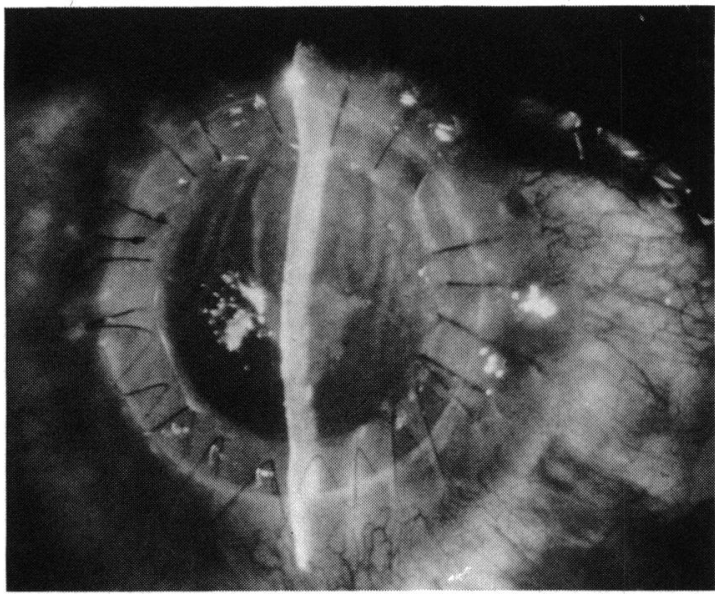

Fig. 3 Two weeks after resuture of traumatic wound dehiscence the original graft remains quite oedematous. Interrupted sutures have reapproximated the tissue from 8 o'clock to 40 'clock. Other interrupted sutures are tied to the ends of the broken running suture inferiorly, and the knots are buried (case 4).

suture underwent an uncomplicated postoperative course such that at 5 weeks the visual acuity with pinhole was $6 / 12(20 / 40)$. On 24 October, 8 weeks after keratoplasty, the patient was accidentally struck in the operated eye by his 3-year-old daughter's finger. He noted pain, blurred vision, and a wet sensation on his left cheek. At the Wilmer Institute in the emergency room the keratoplasty wound was found to have dehisced superiorly and the corneal button protruded between the eyelids, hinged by the remaining inferior sutures. At that time the lids were gently opened, the graft was repositioned, and the lids were taped closed. At surgery soon thereafter the lens was found to be absent, and the vitreous had prolapsed through the corneal wound. A generous anterior vitrectomy was performed, and the graft was resutured in place with interrupted $10-0$ monofilament nylon suture. The loose ends of the running suture inferiorly were tightened and tied to interrupted sutures, and all knots were buried in cornea. In the early postoperative period the graft

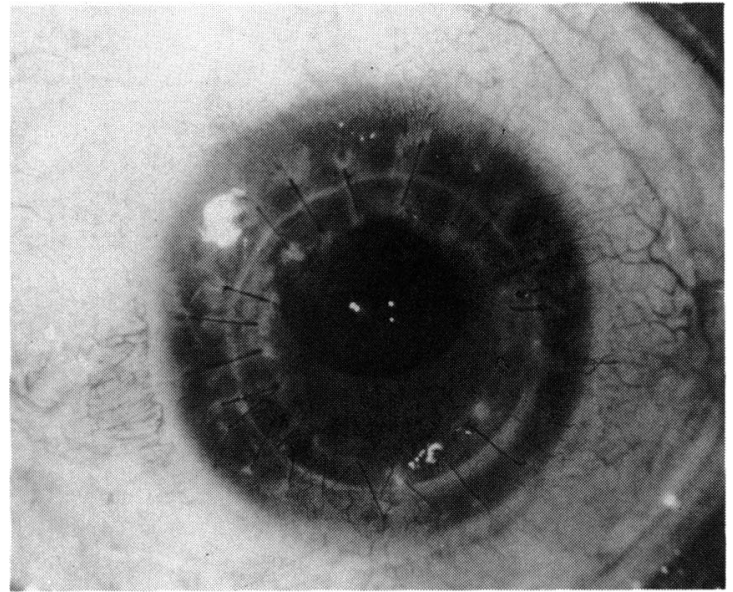

Fig. 4 Six months after wound repair the original corneal button is clear (case 4).

was thick and oedematous (Fig. 3), but it gradually cleared (Fig. 4), yielding a visual acuity of 6/15(20/50).

Three months after the graft was resutured the patient was in a motor accident, immediately after which he noted a 'curtain' over the visual field of the left eye. A retinal detachment was found, and the repair required 2 operative procedures. A macular pucker ensued, reducing the visual acuity to a $6 / 60$ (20/200) level with correction. However, the graft itself has remained crystal clear. In September 1978, 3 years after injury, a spontaneous peeling of the preretinal membrane was observed, and the visual acuity became 6/31 (20/70). The graft remains clear.

\section{Discussion}

All 4 patients were young males who had had penetrating keratoplasty for keratoconus (Table 1). Keratoconus is a common indication for penetrating keratoplasty, ${ }^{6}$ and keratoconus is common among younger persons. Moreover young males as a group are the most prone to ocular injury. ${ }^{7}$ Thus, although 4 other traumatic postkeratoplasty dehiscences have been reported in young males with keratoconus, ${ }^{45}$ we believe it is the exposure of younger persons to the

Table 1 Details of patients

\begin{tabular}{|c|c|c|c|c|c|c|c|}
\hline Case & Age & Sex & $\begin{array}{l}\text { Sutures present at } \\
\text { injury }\end{array}$ & $\begin{array}{l}\text { Interval (months) } \\
\text { keratoplasty to } \\
\text { dehiscence }\end{array}$ & Lens & $\begin{array}{l}\text { Follow-up } \\
\text { (months) }\end{array}$ & Visual outcome \\
\hline $\begin{array}{l}1 \\
2 \\
3 \\
4\end{array}$ & $\begin{array}{l}20 \\
24 \\
30 \\
30\end{array}$ & $\begin{array}{l}\mathbf{M} \\
\mathbf{M} \\
\mathbf{M} \\
\mathbf{M}\end{array}$ & $\begin{array}{l}\text { Interrupted } \\
\text { Running } \\
\text { Removed } \\
\text { Running }\end{array}$ & $\begin{array}{l}21 / 2 \\
31 / 2 \\
72 \\
21 / 2\end{array}$ & $\begin{array}{l}\text { Clear } \\
\text { In vitreous } \\
\text { Lost } \\
\text { Lost }\end{array}$ & $\begin{array}{l}23 \\
59 \\
29 \\
35\end{array}$ & $\begin{array}{l}20 / 30+1 \\
20 / 20 \\
20 / 20 \\
20 / 70^{*}\end{array}$ \\
\hline
\end{tabular}

*Macular pucker following 2 scleral buckling procedures. 
risk of trauma rather than any basic defect of wound healing in keratoconus that accounts for the prevalence of wound dehiscence in this group.

None of our patients was wearing protective wear. One patient received a blow to the eye during a bar-room brawl, one was struck by a Frisbee ricochet, one was struck by a champagne cork at a party, and one was accidentally poked in the operated eye by his 3-year-old daughter's finger during play. The force of the trauma was great enough to expel the lens through the wound dehiscence in 2 cases, the lens was dislocated and fell posteriorly in one case, while the lens remained in place in only one. In Raber $e t$ al.'s series ${ }^{5}$ the lens was lost at the time of injury or surgical repair in 6 of their 7 phakic patients.

In 3 patients the injuries occurred rather soon after surgery: 2 of the injuries occurred at $2 \frac{1}{2}$ months and another was at $3 \frac{1}{2}$ months after operation. In each of these cases the operated eyes were receiving topical corticosteroids. The $10-0$ monofilament nylon sutures were still present. In 2 cases the running sutures broke and the wounds were dehiscent superiorly, whereas in case 2 with interrupted sutures the inferior sutures broke. Our case 4 was a man who had received keratoplasty 5 years before. He had severe trauma to the eye, resulting in inferior rupture of the keratoplasty wound. While our cases showed equal representation of superior and inferior dehiscences, 10 of Raber et al's 12 cases $^{5}$ suffered superior wound rupture, and 10 had nylon sutures still in place. The case described by Polack and Binder ${ }^{4}$ occurred one week after suture removal at $3 \frac{1 / 2}{2}$ months after keratoplasty.

Gassett and Dohlman ${ }^{8}$ have shown in the rabbit that by about 3 months after keratoplasty the tensile strength of a keratoplasty wound is only $50 \%$ of that of the normal intact tissue. Thus it is not at all surprising that ocular injury to a patient at $3 \frac{1}{2}$ months should result in dehiscence in the keratoplasty wound rather than rupture of the globe elsewhere. Our case of late wound dehiscence is similar to those reported by Friedman, ${ }^{3}$ both occurring 4 and 5 years after keratoplasty. In each case the severe ocular trauma resulted in dehiscence of the keratoplasty wound, which suggests that surgical corneal wounds may never achieve the strength of normal cornea. The use of topical corticosteroids undoubtedly contributes to the prolonged weakness of corneal incisions.

In each of these cases the patient received primary resuturing of his corneal graft after the trauma. This was done despite the fact that all of these grafts appeared oedematous and opaque. Nevertheless the grafts went on to deturgesce slowly and to regain excellent clarity. With follow-up varying from 23 months to 5 years the grafts all remained clear. The visual acuity is excellent in 3 cases, 2 having $6 / 6$ $(20 / 20)$ vision and one having $6 / 9(20 / 30)$ vision. The fourth has 6/21 (20/70) acuity because of macular pucker after 2 scleral buckling procedures for traumatic retinal detachment. In Raber et al.'s series the final visual acuity was better than $6 / 60(20 / 200)$ in only 4 patients. Regrafts were carried out at some time after injury in 4 eyes, and one other patient was awaiting regraft

On the basis of these experiences we suggest the following approach. Under general anaesthesia the original graft should be repositioned and resutured in the recipient bed with interrupted $10-0$ monofilament nylon suture as soon as possible. If the patient has been rendered aphakic by the injury, a Flieringa ring should be sutured to the globe to give support, and then an anterior vitrectomy should be performed. Cultures should be taken and the patients treated with prophylactic antibiotics. Postoperatively the physician should exercise patience in waiting for the graft to clear. We also suggest the use of safety glasses by all young patients after penetrating keratoplasty in the hope of preventing these severe (and sometimes disastrous) ocular injuries.

Endothelial cell loss occurs after intraocular surgery. ${ }^{9}$ Presumably the amount of cell loss parallels the degree of endothelial trauma that occurs intraoperatively. Most corneal surgeons have the impression that almost any touch of the corneal endothelium at the time of grafting will result in corneal oedema. One would assume that an injury serious enough to cause postoperative wound dehiscence, expulsion of the lens, and loss of vitreous through the wound opening (thus resulting in vitrealendothelial touch and a temporarily flat anterior chamber) would also cause considerable endothelial trauma. In our cases, however, the graft endothelium apparently had enough functional reserve to withstand the blow to the eye; and despite the immediate post-traumatic oedema, corneal function improved after repair of the dehiscence so as to restore graft clarity in each case. Therefore some physiological change must occur in the donor endothelium after it has adapted to the recipient eye for several months to allow it to withstand such severe insults as occur with traumatic wound dehiscence, while much milder trauma at initial transplantation surgery may result in permanent corneal oedema. It is of interest that the case of graft failure reported after traumatic wound dehiscence that was studied by Polack and Binder ${ }^{4}$ showed absence of Descemet's membrane and the endothelium over half of the graft specimen, which indicates why the graft failed to clear.

This work was supported in part by NIH academic investigator award EY-00156, Research to Prevent Blindness James L. Adams award, and Fight for Sight, Inc. grant in aid (Dr. Kenyon). 


\section{References}

1. Binder PS, Abel RJr, Polack FM, Kaufman HE. Keratoplasty wound separation. Am J Ophthalmol 1975; 80: 109-15.

2 Brown SI, Tragakis MP. Wound dehiscence with keratoplasty: Complication of the continuous-suture technique. Am J Ophthalmol 1971; 72: 115-6.

3 Friedman AH. Late traumatic wound rupture following successful partial penetrating keratoplasty. Am J Ophthalmol 1973; 75: 117-20.

4 Polack FM, Binder PS. Detachment of Descemet's membrane from grafts following wound separation: light and scanning electron microscopic studv. Ann Ophthalmol 1975: 7: 47-54

5 Raber IM, Arentsen JJ, Laibson PR. Traumatic wound dehiscence after penetrating keratoplasty. Arch Ophthalmol 1980; 98: 1407-9.

6 Arentsen JJ, Morgan B, Green WR. Changing indications for keratoplasty. Am J Ophthalmol 1976; 81: 313-8.

7 Eagling EM. Perforating injuries of the eye. Br JOphthalmol 1976; 60: 732-6.

8 Gasset AR, Dohlman CH. The tensile strength of corneal wounds. Arch Ophthalmol 1968; 79: 595-602.

9 Bourne WM, O'Fallon WM. Endothelial cell loss during penetrating keratoplasty. Am J Ophthalmol 1978; 85: 760-6. 